\title{
Bir Sigara Bırakma Polikliniğine Başvuran Hastaların Özellikleri
}

\section{Characteristics of Patients Admitted to a Smoking Cessation Policlinic}

\author{
Mehmet KABAK ${ }^{1}(\mathbb{D})$, İclal HOCANLI ${ }^{2}(\mathbb{D})$, Barış Çíl ${ }^{1}(\mathbb{D})$
}

${ }^{1}$ Mardin Eğitim ve Araştırma Hastanesi, Göğüs Hastalıkları Bölümü, Mardin,TÜRKiYE

2 Sağlık Bilimleri Üniversitesi, Şanlıurfa Mehmet Akif İnan Eğitim ve Araştırma Hastanesi, Göğüs Hastalıkları,Şanlıurfa,TÜRKiYE

Öz.

Amaç: Sigara, önlenebilir ölüm ve hastalıkların en sık nedenidir. Ülkemiz, sigara içme oranı yüksek olan Avrupa ülkelerinden biridir. Toplumsal bilinçlenme, eğitim ve sosyal durumların etkisiyle sigara bırakma polikliniklerine başvurular artmaktadır. Bu çalışmada, hem sigara polikliniğimizdeki sigara bırakma durumunu hem de sigara bırakma için 12 haftalık standart bir vareniklin rejimini ve 10 haftalık standart bir transdermal nikotin replasman tedavisi (NRT) rejiminin bırakma üzerindeki etkisini tartışmayı amaçladık.

Materyal ve Metod: Bu çalışmaya Ocak 2015 ve Ocak 2018 yılları arasında sigara bırakma polikliniğine başvuran, sigara bırakma tedavisi başlanmış 845 hasta retrospektif olarak incelendi.

Bulgular: Çalışmaya dahil edilen hastalar sigara bırakma durumuna göre karşılaştırıldı. íki grup arasında yaş ve cinsiyet açııından istatiksel olarak anlamlı fark saptanmadı $(p=0.622, p=0.241)$. Sigara bırakan grupta Fagerstrom Nikotin Bağımlılık Skoru (FNBS) 6.12 \pm 0.9 iken, sigara bırakmayan grupta $8.45 \pm 1.1$ idi ve gruplar arasında istatiksel olarak anlamlı farklıık saptandı $(p=0,04)$. Hastaların $\% 80,5^{\prime} i$ vareniklin, $\% 19,5^{\prime} i$ nikotin bandı kullanmıştı. Hastalar aldığı ilaca göre karşılaştıııldı. Sigara bırakmada Vareniklin ve nikotin bandı arasında istatistiksel anlamlı fark saptanmadı $(p=0.707)$. Ayrıca iki grup yaş ve cinsiyet açısından karşılaştıııldı. İki grup arasında yaş $(p<0,001)$ açından anlamlı fark saptanırken, cinsiyet $(p=0,405)$ açısından anlamlı fark saptanmadı. Vareniklin alan grupta FNBS $6,95 \pm 0,9$ iken, NRT alan grupta $7,01 \pm 0,7$ olarak hesaplanmış olup iki grup arasında anlamlı fark saptanmadı $(p=0,506)$.

Sonuç: Yaş ve cinsiyet gibi demografik özelliklerin sigara bırakmayı etkilemediği, ancak FNBS düşük olmasının sigarayı bırakmada etkili olduğu görüldü. Ayrıca sigara bırakmada ilaçlar arasında herhangi bir fark olmadığı saptanmıştır.

Anahtar Kelimeler: Sigara Bırakma, Vareniklin, Nikotin Replasman Tedavisi

\section{Abstract}

Background: Smoking is the most common cause of preventable death and disease. Our country is one of the European countries with a high smoking rate. With the effect of social awareness, education and social situations, applications to smoking cessation outpatient clinics are increasing. In this study, we aimed to discuss both smoking cessation in our outpatient clinic and the effect of a standard 12-week varenicline regimen for smoking cessation and a standard 10-week transdermal nicotine replacement therapy (NRT) regimen on cessation.

Materials and Methods: 845 patients who applied to smoking cessation clinic between January 2015 andJanuary 2018 were started retrospectively.

Results: The patients included in the study were compared according to their smoking cessation status. There was no statistically significant difference between the two groups in terms of age and gender $(p=0.622, p=0.241)$. While the Fagerstrom Nicotine Dependence Score (FNBS) was $6.12 \pm 0.9$ in the group who quit smoking, it was $8.45 \pm 1.1$ in the group who did not quit smoking, and there was a statistically significant difference between the groups $(p=0.04)$. $80.5 \%$ of the patients used varenicline, $19.5 \%$ of them used nicotine patch. The patients were compared according to the drug they took. There was no statistically significant difference between Varenicline and nicotine patch in smoking cessation ( $p=0.707)$. In addition, the two groups were compared in terms of age and gender. While there was a significant difference between the two groups in terms of age $(p<0.001)$, there was no significant difference in terms of gender $(p=0.405)$. While FNBS was $6.95 \pm 0.9$ in the varenicline group, it was $7.01 \pm 0,7$ in the NRT group, and there was no significant difference between the two groups $(p=0.506)$.

Conclusions: It was observed that demographic characteristics such as age and gender did not affect smoking cessation, but low FNBS was effective in quitting smoking. In addition, it was determined that there was no difference between drugs in smoking cessation.

Keywords: Smoking Cessation, Varenicline, Nicotine Replacement Therapy

\section{Sorumlu Yazar / Corresponding Author}

Dr. Mehmet KABAK

Mardin Eğitim ve Araştırma Hastanesi Göğüs Hastalıkları Bölümü, Mardin/TÜRKIYE

E-mail: mehmetkabak8@hotmail.com Geliş tarihi / Received: 13.08.2021

Kabul tarihi / Accepted: 02.11.2021

DOI: 10.35440/hutfd.982507 


\section{Giriş}

Sigara, önlenebilir ölüm ve hastalıkların en sık nedenidir. Dünya Sağlık Örgütü'ne (DSÖ) göre dünyada 1,4 milyar kişi sigara kullanmakta ve her yıl yaklaşık 6 milyon kişi sigaradan dolayı yaşamını yitirmektedir. Ülkemizde de yılda 100 bin kişi sigara nedeniyle ölmektedir. Bu sayının 2030 yılına kadar dünyada 8,4 milyon kişiye, ülkemizde ise 240,000 kişiye yükseleceği öngörülmektedir (1).

Ülkemiz, sigara içme oranı yüksek olan Avrupa ülkelerinden biridir. İnsanlar sigaranın bağımlığa neden olmadığını düşünse de içinde yer alan nikotin bağımlılığa neden olmaktadır (2). Sigara içenlerin büyük bir bölümü yaşamının herhangi bir döneminde sigarayı bırakmayı ya düşündüğü ya da denediği bildirilmektedir. Çoğu içici sigara bırakmayı yardım almadan denemekte ve sigara bırakma denemesi kısa süre başarısız bir şekilde sonuçlanmaktadır (2).

Ülkemizde de toplumsal bilinçlenme, eğitim ve sosyal durumların etkisiyle sigara bırakma polikliniklerine başvurular gün geçtikçe artmaktadır. Bu polikliniklerde hem davranışsal eğitim hem de medikal destek verilmektedir. Sigarayı bırakma tedavileri, hastalıkları önlemek amacıyla kullanılan en ucuz tedavi yöntemleridir. Sigara bırakma tedavisinde, onaylanan farmakolojik tedaviler arasında çeşitli nikotin replasman tedavisi (NRT), sürekli salınımlı (SR) bupropion ve en son olarak vareniklin formları bulunur $(3,4)$. Vareniklin, Mayıs 2006'da ABD'nde FDA ve Eylül 2006'da ABD Tıbbi Maddelerin Değerlendirilmesi Avrupa Ajansı (EMEA) tarafından tütün bağımlıı̆̆ının tedavisi için lisanslı bir nikotinik asetilkolin reseptör kısmi agonistidir (5). Yapılan bir çalışmada Vareniklin'in sigara bırakma oranı \%69,3 iken, NRT'in sigara bırakma oranı \%30 olarak ölçülmüştür (6). Yan etkisinin az olması ve etkinliğinin kanıtlanmış olması sebebiyle eczane ve genel satışlar yoluyla kolay erişilebilirlik sağlar.

Bu çalışmada sigara bırakma için 12 haftalık standart bir vareniklin rejimini ve 10 haftalık standart bir transdermal nikotin replasman tedavisi (NRT) rejiminin sigara bırakmadaki etkinliğini karşılaştırmayı amaçladık.

\section{Materyal ve Metod}

Bu çalışmaya Ocak 2015 ve Ocak 2018 yılları arasında sigara bırakma polikliniğine başvuran, sigara bırakma tedavisi başlanmış 845 hasta retrospektif tarama ile alındı. Çalışma için etik kurul onayı alındı (Etik kurul onay no: HRU/21.07.16, etik kurul onay tarih:29.03.2021)

Hastaların sistemik fizik muayenesi yapıldı. Bunun yanında hastalara sigaranın zararlarıyla ilgili kısa bir eğitim verildi. Bir forma hastaların sigara bırakma tedavisinde kullandığı ilaç, birinci yılın sonunda sigara bırakma durumu, yaş ve cinsiyeti kaydedildi. Hastaların sigara paket/yıl durumu kaydedildi. Tüm hastalara genel bir değerlendirme ile birlikte, Fagerström nikotin bağımlılık testini de içeren bir sigara sorgulama formu uygulandı (7).

Son 6 ay içinde kanser öyküsü, herhangi bir ciddi hastalık, depresyon veya diğer psikolojik bozukluk tanısı veya tedavisi, önceki 12 ay içinde uyuşturucu veya alkol bağımlılığı varsa katılımcılar dışlandı.
Diğer dışlama kriterleri, ilaçlara veya yapışkan bantlara allerjisi olanlar, nikotin replasman bantlarının yapışmasına engel cilt bozuklukları olanlar, sistolik kan basıncı $150 \mathrm{~mm}$ $\mathrm{Hg}$ veya diastolik kan basıncı $95 \mathrm{~mm} \mathrm{Hg}$ üstünde olan hastalar, klinik olarak önemli böbrek veya karaciğer yetmezliği olanlar, Vareniklin veya NRT gibi ilaçların etkisini etkileyebilecek ilaç kullananlar, çalışmaya başlamadan 6 ay içerisinde Vareniklin tedavisi kullanıp ya da NRT'nin herhangi bir formunu kullanıp başarısız olanlar çalışma dışı bırakıldı. Sigara bırakma polikliniğine başvuran hastalara, kontrendikasyonları dışlandıktan sonra ücretsiz vareniklin veya NRT başlandı. Hastaya Vareniklin verilmesinde herhangi bir kontrendikasyon varsa ve/veya Vareniklin temin edilemediği durumlarda NRT verildi (Şekil 1). Vareniklin tedavisi olarak hastalara 12 hafta boyunca oral tablet başlandı. Hastalarla 4 hafta arayla 3 görüşme, sonrasında 6 . ayın sonunda görüşme yapıldı. 1. yıl sonunda ise telefonla görüşmeler yapıldı. Kayıtlar sadece hastanın beyanına göre yapıldı.

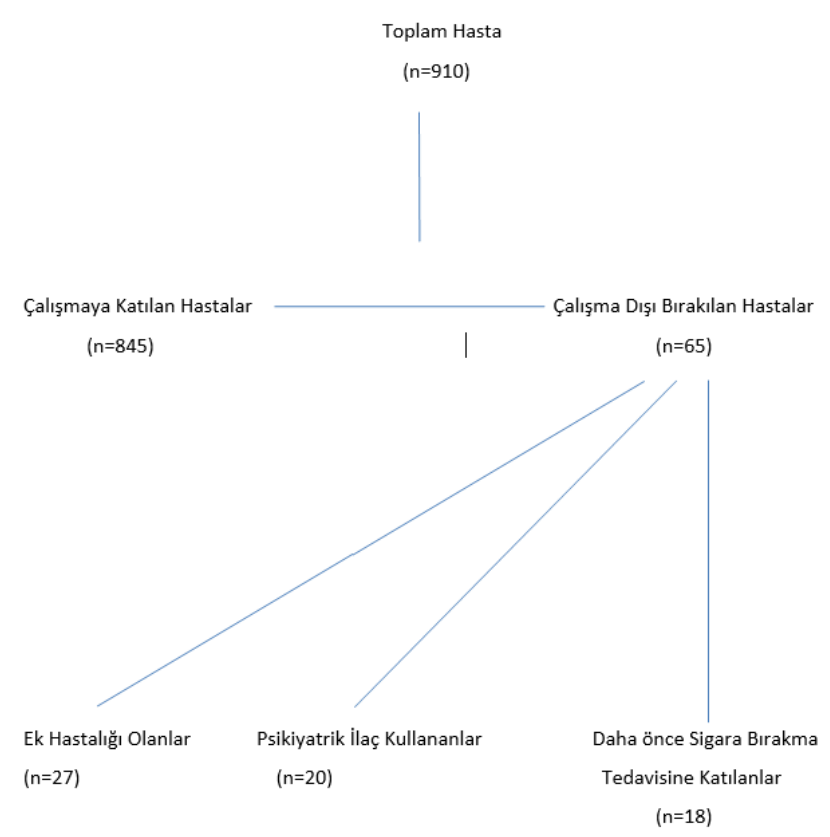

Şekil 1. Çalışma katılan ve dışlanan hastalar

Nikotin replasmanı tedavisinde günde 20 adet ve üzeri sigara içen hastalara $21 \mathrm{mg} / 24$ saat/gün transdermal nikotin flasterleri (Nicotinell TTS) başlanmakta ve dörder haftalık aralıklarla 14 ve $7 \mathrm{mg}$ ile üç ay boyunca devam edildi. Günde yirmi adetten daha az sigara içenlere ise $14 \mathrm{mg} / 24$ saat/gün ve $7 \mathrm{mg} / 24$ saat/gün dozda nikotin replasmanı uygulandı ve aynı sürelerle azaltıldı. Hastalar bu süre içinde kontrole çağırıldı. Hastalarla birinci yıl sonunda telefon görüşmesi yapıldı. Hastalar birinci yılın sonunda sigarayı bırakanlar ve bırakmayanlar olmak üzere iki gruba ayrıldı. Hastaların demografik ve klinik verileri iki grup arasında karşılaştırıldı.

\section{istatistiksel analizler}

SPSS for Windows 22.0 sürümü (SPSS Inc., IL, ABD) kulla- 
nıldı. Tanımlayıcı istatistikler, medyan (minimum-maksimum) olarak sunuldu. Verilerin normal dağılıp dağılmadığını değerlendirmek için Kolmogorov-Smirnov testi kullanıldı. Normal dağılıma uymayan veriler, Mann-Whitney U testi kullanılarak karşılaştırılırken, sayı ve yüzde olarak ifade edilen kategorik veriler ki-kare testi kullanılarak karşılaştırıldı. Hipotezler çift yönlü olup, \%95 güven aralığında $\mathrm{p} \leq 0.05$ değeri istatistiksel olarak anlamlı kabul edildi.

\section{Bulgular}

Çalışmaya 660'ı erkek ve 185 'i kadın olmak üzere toplam 845 hasta dahil edildi. Her iki grup arasında yaş ve cinsiyet açısından istatiksel farklılık saptanmadı. (Tablo 1). íki grup arasında Fagerström Nikotin Bağımlılık Skoru(FNBS) hesaplandı. İki grup arasında istatistiksel olarak anlamlı farklılık mevcuttu ( $p=0.04)$ (Tablo 1).

Tablo 1. Demografik ve klinik verilerin karşılaştırılması

\begin{tabular}{|c|c|c|c|c|}
\hline & & $\begin{array}{c}\text { Sigara } \\
\text { Bırakanlar } \\
(\mathrm{n}=\mathbf{3 8 5})\end{array}$ & $\begin{array}{c}\text { Sigara } \\
\text { Bırakmayanlar } \\
(n=460)\end{array}$ & $\mathbf{P}$ \\
\hline Yaş, yıl & & 29 (19-70) & $32(18-71)$ & 0.622 \\
\hline \multirow{2}{*}{ Cinsyet,\% } & Erkek & $285(43.2)$ & $375(81.6)$ & \multirow{2}{*}{0.241} \\
\hline & Kadın & $100(54.1)$ & 85 (45.9) & \\
\hline FNBS & & $6,12 \pm 0,9$ & $8,45 \pm 1,1$ & 0,040 \\
\hline Vareniklin & & 305 (44.9) & $375(55.1)$ & 0.709 \\
\hline NRT & & 80 (48.5) & $85(51.5)$ & 0.710 \\
\hline
\end{tabular}

Hastaların \%80,5'i vareniklin kullanırken, \%19,5'i nikotin bandı kullanmıştı. Çalışma sonunda ulaşılan sigarayı bırakma oranı \%45,6 olarak saptandı. Sigarayı bırakanların \%79,3'ü vareniklin, \%20.7'si NRT kullanmışken sigarayı bırakamayanlarda bu oranlar sırasıyla \%81.6 ve \%18.4 idi. Farmakolojik destek açısından her iki grup arasında istatiksel anlamlı bir değer elde edilmedi $(p=0.709, p=0.710)$ (Tablo 1).

Tablo 2. Farmakolojik Ajanların Sigara Bırakma Arasındaki Fark

\begin{tabular}{|c|c|c|c|c|}
\hline & & Vareniklin & NRT & $p$ \\
\hline \multicolumn{2}{|c|}{ Yaş (min-max) } & $(19-71)$ & $(18-60)$ & $<0,001$ \\
\hline \multirow{2}{*}{ Cinsiyet } & Erkek & 540 & 120 & \multirow{2}{*}{0,405} \\
\hline & Kadın & 140 & 45 & \\
\hline FNBS & & $6,95 \pm 0,9$ & $7,01 \pm 0,7$ & 0,506 \\
\hline \multirow{2}{*}{$\begin{array}{l}\text { Sigara } \\
\text { Bırakma } \\
\text { Durumu }\end{array}$} & Evet & $305(\% 44,9)$ & $375(\% 55,1)$ & \multirow[b]{2}{*}{0,707} \\
\hline & Hayır & $80(\% 48,5)$ & $85(\% 51,5)$ & \\
\hline
\end{tabular}

Ayrıca hastalar kullandığı ilaç açısından iki gruba ayrıldı. Sigara bırakmada Vareniklin ve nikotin bandı arasında istatistiksel anlamlı fark saptanmadı ( $p=0.707)$. Ayrıca iki grup yaş ve cinsiyet açısından karşılaştırıldı. Iki grup arasında yaş $(p<0,001)$ açından anlamlı fark saptanırken, cinsiyet $(p=0,405)$ açısından anlamlı fark saptanmadı. Vareniklin

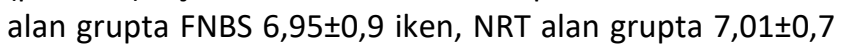
olarak hesaplanmış olup iki grup arasında anlamlı fark saptanmadı $(p=0,506)$.

\section{Tartışma}

Çalışmamızda sigara bırakma oranımız \%45,6 idi. FNBS'nin düşük olması sigaranın bırakılmasında en önemli faktörlerden biridir. Çalışmamız sigara bırakmada, kullanılan ilaçlar arasında herhangi bir fark olmaksızın, ilaç desteğinin olumlu etkisini göstermesi açısından önem taşımaktadır.

Son yıllarda tüm dünyada tütün bağımlılığı ile önemli bir mücadele verilmektedir. Yapılan bir çalışmada insanların sosyal, psikolojik ve farmakolojik faktörler nedeniyle sigara içtiği bildirilmiştir (8). Yapılan bir çalışmada davranışsal eğitim ile birlikte farmakolojik tedavinin sigara bırakma başarısını artırdığı gösterilmiştir (9). Her yıl sigara içenlerin çoğunda sigarayı bırakma denemesi başarısız sonuçlanmaktadır. Yapılan bir çalışmada sigara bırakmadaki başarısızlığının nedenlerinden başında yoksunluk semptomlarının olduğunu bildirmişlerdir (10). Bu nedenle tütün kontrolünün temelini sağlayan, sigara bırakma poliklinikleri oluşturulmuştur. Tüm dünyada ve ülkemizde sigara bırakma polikliniklerinin sayısı gün geçtikçe artmaktadır (2). Sigara bırakmaya gelen kişi için; öncelikle sigara bırakma ile ilgili bilgilendirme ve sigara bağımlılık değerlendirilmesi yapılmaktadır. Uygun görüldüğünde psikolojik tedavi yöntemlerinin uygulanması ve düzenli izlenmesi planlanmaktadır (11). Bu tedavi, özel eğitimli bir personel tarafından kısa görüşmelerden başlanarak, daha detaylı görüşmelerle devam etmektedir. Bu görüşmelerde; sigara kullanıp kullanmadığı, bırakmanın tavsiye edilmesi, bırakmayı ne kadar istediği sorulmaktadır, ayrıca istekli olanlara tedavi desteğinin uygulanması ve takip görüşmelerinin planlanması yapılmaktadır (11). İş yeri ve ev stresi gibi sebepler kişinin tekrar sigaraya başlamasına sebep olabileceğinden, kişiyle beraber yaşayan partneri de bu sürece dahil edilip bırakma kolaylaştırılabilir. Sigara bırakma için, eğitim ve psikolojik destek ile birlikte farmakolojik tedavi verilmesinin başarıyı arttırdığı gösterilmiştir (6). Sigara kullanımı, kişiye bilişsel, davranışsal ve fizyolojik boyutta etkilere neden olmaktadır. Bu nedenle sigaranın bırakılmasında birtakım zorluklar karşımıza çıkmaktadır. Yapılan bir çalışmada 3.ayda bırakma oranları \%54-65 aralığında bulunmuştur. Ülkemizde yapılan farklı çalışmalarda ise 1 . yılın sonunda başarı oranı \%21,6 ile \%45 arasında olduğu bildirilmiştir (11-13). Literatür verilerine paralel olarak, bizim çalışmamızda da 1 . yılın sonunda olgularımızın \%45,6'sı sigarayı bırakmıştır. Özellikle sıkı takipler, tedaviye uyumu ve sigara bırakma başarısını arttırdığı için kesinlikle aksatılmamalıdır.

Yaş, cinsiyetin sigara bırakmaya etkisi değerlendirilmiştir. Bazı çalışmalar erkeklerin sigarayı daha kolay bıraktığını gösterse de yapılan çalışmaların çoğunda cinsiyetin sigara bırakma başarısına etkisi olmadığını gösterilmiştir (14-17). Bunun nedeninin ise son zamanlarda kadınlarda da sigara içme oranının artmasına bağlı olduğu düşünülmüştür. Bizim çalışmamızda da sigara bırakanlarda erkek sayısı yüksek olmasına rağmen istatistiksel olarak önemli farklılık saptanmadı. Ayrıca bazı çalışmalar yaş arttıkça sigara bırakma başarısının arttığını, özellikle yaşlı hastalarda, kronik hastalıkların eşlik etmesiyle birlikte sigara içme oranının azaldığı 
göstermişlerdir (9). Çalışmamızda ise yaş bakımından her iki grup arasında anlamlı farklılık yoktu.

Yapılan çalışmalarda ilaç desteğinin sigara bırakmada etkili olduğu gözlenmiştir. Ancak iki grup ilaç tedavisi arasında herhangi bir fark gözlenmemiştir $(9,10,18)$. Bunun yanı sıra yapılan başka çalışmalarda ise diğer farmakolojik tedavilerin NRT'ye göre daha üstün olduğu gösterilmiştir (19-22). Çalışmamızda, hastalara davranışsal terapiyle birlikte farmakolojik destek tedavisi olarak Vareniklin ve NRT verildi. Ancak her iki ilacın, birinci yıl sonunda sigarayı bırakma oranları arasında anlamlı fark görülmedi.

Günlük içilen sigara sayısı, FNBS ve paket/yıl değeri sigara bırakmada etkili faktörlerdir. Bu faktörler ile sigara bırakma arasında ters ilişki mevcuttur $(23,24)$. Renaud ve ark. çalışmalarında, nikotin bağımlılığı ve sigara tüketimi fazla olanların, sigara bırakma oranlarının düşük olduğunu göstermişlerdir (14). Gorecka ve ark. ise düşük FNBS'nin sigara bırakmada olumlu ilişkisi olduğunu bildirmişlerdir (25). Mevcut verilere uygun olarak, bizim çalışmamızda da sigara bırakan grupta FNBS'nin anlamlı derecede düşük olduğu gözlendi. Bu çalışmada ek hastalıkları olanların dışlanması, 6. ay ve 12. ayın sonundaki görüşmelerin yüz yüze yapılmaması, ayrıca gruplar arası hasta sayılarının belirgin farklılık göstermesi çalışmamızı kısıtlayan nedenlerdir.

\section{Sonuç}

Sonuç olarak; çalışmada yaş, cinsiyet gibi verilerin sigara bırakmayı etkilemediği gösterilmiştir. Ancak FNBS'nin düşük olmasının sigarayı bırakmada etkili olduğu görülmüştür. Sigarayı bıraktırmak hem hasta için hem de doktor için zaman alıcı ve zor bir uygulamadır. Sigara bırakma polikliniklerinde, davranışsal eğitimin yanında uygun farmakolojik destek tedavisi verilmeli ve gerekli tedavilerin uygun bir şekilde kullanılması, sigara bırakma başarısını arttırdığı için hastalar yakından takip edilmelidir.

Etik onam: için Harran Üniversitesi Tıp Fakültesi Klinik Araştırmalar Etik Kurulu'ndan etik onam alındı (29.03.2021 tarihli, $\mathrm{HRU} / 21.07 .16)$.

\section{Yazar Katkıları:}

Konsept: M.K., B.Ç.

Literatür Tarama: I.H., M.K.

Tasarım: i.H., M.K.

Veri toplama: M.K., I.H., B.Ç.

Analiz ve yorum: I.H., M.K.

Makale yazımı: i.H., M.K.

Eleştirel incelenmesi: M.K., B.Ç., I.H.

Fon sağlama (mevcut ise):

Çıkar Çatışması: Yazarlar çıkar çatışması beyan etmemişlerdir. Finansal Destek: Yazarlar finansal destek beyan etmemişlerdir

\section{Kaynaklar}

1. Mathers CD, Loncar D. Projections of global mortality and burden of disease from 2002 to 2030. PLoSMed. 2006;3(11):e442. doi: 10.1371/journal.pmed.0030442.

2. Yaşar Z, Kurt ÖK, Talay F, Kargı A. One-Year Follow up Results of Smoking Cessation Outpatient Clinic: Factors Affecting The Cessation of Smoking. Eurasian J Pulmonol 2014; 16(2): 99-104

3. Zhong $Z$, Zhao $S$, Zhao $Y$, Xia S. Combination therapy of varenicline and bupropion in smoking cessation: A meta-analysis of the randomized controlled trials. Compr Psychiatry. 2019 Nov; 95: 152125.

4. Nagano T, Katsurada M, Yasuda Y, Kobayashi K, Nishimura Y. Current pharmacologic treatments for smoking cessation and new agents undergoing clinical trials. Ther Adv Respir Dis. 2019 JanDec;13:1753466619875925.

5. Tønnesen P, Carrozzi L, Fagerström KO, Gratziou C, Jimenez-Ruiz C, Nardini S, et al. Smoking cessation in patients with respiratory diseases: a high priority, integral component of therapy. EurRespir J. 2007;29(2):390-417.

6. Berkeşoğlu Ç, Özgür ES, Demir AU. Sigara bırakma başarısını etkileyen faktörler. Mersin Univ Saglık Bilim Derg 2018;11(3):355-65.

7. Heatherton TF, Kozlowski LT, Frecker RC, Fagerström KO. The Fagerström Test for Nicotine Dependence: a revision of the Fagerström Tolerance Questionnaire. Br J Addict. 1991;86(9):1119-27.

8. A clinical practice guideline for treating tobacco use and dependence: A US Public Health Service report. The Tobacco Use and Dependence Clinical Practice Guideline Panel, Staff, and Consortium Representatives. JAMA. 2000;283(24):3244-54.

9. Argüder $E$, Karalezli $A$, Hezer $H$, Kılıç H , Er M , Hasanoğlu HC ve ark Sigara Bırakma Başarısını Etkileyen Faktörler. Turk Toraks Derg 2013; 14: 81-7

10. Yılmaz A, Turan A. Sigara Bırakma Tedavisindeki Hastalarımızın Genel Özellikleri Ve Tedavi Başarısını Etkileyen Faktörler İzmir Göğüs Hastanesi Dergisi, Cilt Xxıx Sayı 3, 2015

11. Yaşar Z, Kurt ÖK, Talay F, Kargı A. Bir Yıllık Sigara Bırakma Poliklinik Sonuçlarımız: Sigara Bırakmada Etkili Olan Faktörler. Eurasian J Pulmonol 2014; 16: 99-104

12. Kanık MK, Tözün M. İzmir'de Sigarayı Bırakma Polikliniklerine Başvuranların Sigara ve Diğer Tütün Ürünleri Kullanım Özellikleri ve Nikotin Bağımlıık Durumları ESTÜDAM Halk Sağlığı Dergisi. 2020;5(1):84-95.

13. Kamışlı $S$, Yüce $D$, Küçükçoban Ş, Hayran $M$, Kılıçkap $S$, Çelik I ve ark. Bir Sigara Bırakma Polikliniğinde Uygulanan Psikoeğitimsel Sigara Bırakma Porogramının Etkinliği. Anadolu Hem Sağ Bil Derg, 2017;20(4):235-243

14. Renaud JM, Halpern MT. Clinical management of smoking cessation: patient factors affecting a reward-based approach. Patient Prefer Adherence 2010;4:44150.

15. Sağlam L. Investigation of theresults of a smoking cessation clinic and the factors associated with succes. Turk J MedSci2012; 42:515-22.

16. Wu PC, Hsueh KC, Mar GY, Hsueh SC, Tu MS, McRobbie $\mathrm{H}$, et al. Gender Differences in Outcome of an Attempt 
to Stop Smoking Among Smokers Attending a Smoking Cessation Clinic in Taiwan: 3-Year Follow-Up Study. Evaluation \&the health professions. 2016; 39(3):31725

17. Smith PH, Kasza KA, Hyland A, Fong GT, Borland R, Brady $\mathrm{K}$, et al. Gender differences in medication use and cigarette smoking cessation: results from the International Tobacco Control Four Country Survey. Nicotine\&Tobacco Research. 2015; 17(4):463-72.

18. Kanatsız B, Başıllar Ş, Şaylan B, Albay A, Basat SU. Sigara Bırakma Başarısını Etkileyen Faktörler ve Medikal Tedavilerin Değerlendirilmesi Euras J Fam Med 2017;6(2):65-71

19. 19.Patnode CD, Henderson JT, Thompson JH, Senger CA, Fortmann SP, Whitlock EP. Behavioral Counseling and Pharmacotherapy Interventions for Tobacco Cessation in Adults, Including Pregnant Women: A Review of Reviewsforthe U.S. Preventive Services Task Force. Annals of internalmedicine. 2015;163(8):608-21.

20. 20.Cahill K, Stevens $S$, Lancaster T. Pharmacological treatments for smoking cessation. Jama. 2014;311 (2):193-4

21. 21.Mills EJ, Wu P, Lockhart I, Thorlund K, Puhan M, Ebbert JO. Comparisons of high-dose and combination nicotine replacementtherapy, varenicline, and bupropion for smoking cessation: a systematic review and multiple treatment meta-analysis. Annals of medicine. 2012; 44(6):588-97.

22. 22. Anthenelli RM, Benowitz NL, West R, StAubin $L$, McRae T, Lawrence D et al. Neuropsychiatric safety an defficacy of varenicline, bupropion, and nicotine patch in smokers with and with outpsychiatric disorders (EAGLES): a double-blind, randomised, placebo-controlled clinical trial. Lancet. 2016;387(10037):2507-20.

23. 23.Kenford SL, Fiore $M C$, Jorenby $D E$, Smith SS, Wetter D, Baker TB. Predicting smoking cessation. Who will quit with and without the nicotine patch. JAMA. 1994;271(8):589-94.

24. 24.Fernandez E, Garcia M, Schiaffino A, Borras JM, Nebot $M$, Segura $A$. Smoking initiation and cessation by gender and education al level in Catalonia, Spain. PrevMed. 2001;32(3):218-

25. 25.Górecka $D$, Bednarek $M$, Nowiński $A$, Puścińska $E$, Goljan-Geremek A, Zieliński J. Diagnosis of airflow limitation combined with smoking cessation advice increases stop-smoking rate. Chest. 2003;123(6):1916-23. 